(C) The Authors 2016. This is an Open Access article, distributed under the terms of the Creative

Commons Attribution licence (http://creativecommons.org/licenses/by/4.0/), which permits unrestricted

re-use, distribution, and reproduction in any medium, provided the original work is properly cited.

\title{
Dietary intake of manganese and the risk of the metabolic syndrome in a Chinese population
}

\author{
Biao Zhou ${ }^{1} \dagger$, Xuefen $\mathrm{Su}^{2,3} \dagger$, Danting $\mathrm{Su}^{1}$, Fangfang Zeng ${ }^{2,3}$, Maggie Haitian Wang ${ }^{2,3}$, Lichun Huang ${ }^{1}$, \\ Enshan Huang ${ }^{1}$, Yibo Zhu ${ }^{1}$, Dong Zhao ${ }^{1}$, Denghua $\mathrm{He}^{4}$, Xuhui Zhu ${ }^{4}$, Engkiong Yeoh $^{2,3}$, Ronghua Zhang ${ }^{1 *}$ \\ and Gangqiang Ding ${ }^{5 *}$ \\ ${ }^{1}$ Zhejiang Provincial Centre for Disease Control and Prevention, Hangzhou, Zhejiang 310051, People's Republic of China \\ ${ }^{2}$ School of Public Health and Primary Care, Faculty of Medicine, The Chinese University of Hong Kong, Hong Kong, 999077, \\ People's Republic of China \\ ${ }^{3}$ Chinese University of Hong Kong Shenzhen Research Institute, Shenzhen 518057, People's Republic of China \\ ${ }^{4}$ Medical School of Ningbo University, Ningbo, Zhejiang 315211, People's Republic of China \\ ${ }^{5}$ National Institute for Nutrition and Health, Beijing 100050, People's Republic of China
}

(Submitted 24 November 2015 - Final revision received 29 May 2016 - Accepted 6 June 2016 - First published online 7 July 2016)

\section{Abstract}

Animal studies have suggested that Mn might be associated with some components of the metabolic syndrome (MetS). A few epidemiological studies have assessed dietary Mn intake and its association with the risk of the MetS and its components among Chinese adults. In this study, we assessed daily dietary $\mathrm{Mn}$ intake and its relationship with MetS risk among Chinese adults in Zhejiang Province using data from the 5th Chinese National Nutrition and Health Survey (2010-2012). A total of 2111 adults were included. Dietary Mn intake was assessed using 3-d 24-h dietary recalls; health-related data were obtained by questionnaire surveys, physical examinations and laboratory assessments. The mean intake of Mn was 6.07 (SD 2.94) mg/d for men ( $n$ 998) and 5.13 (SD 2.65$) \mathrm{mg} / \mathrm{d}$ for women $(n 1113)$. Rice ( $>42 \%$ ) was the main food source of Mn. The prevalence of the MetS was 28.0\% (590/2111). Higher Mn intake was associated with a decreased risk of the MetS in men (Q4 $v$. Q1 OR $0.62 ; 95 \%$ CI $\left.0.42,0.92 ; P_{\text {trend }}=0.043\right)$ but an increased risk in women (Q4 $v$. Q1 OR 1.56; $95 \%$ CI 1.02, 2.45; $\left.P_{\text {trend }}=0.078\right)$. In addition, Mn intake was inversely associated with abdominal obesity $\left(P_{\text {trend }}=0.016\right)$ and hypertriacylglycerolaemia $\left(P_{\text {trend }}=0.029\right)$ in men, but positively associated with low HDL-cholesterol in both men $\left(P_{\text {trend }}=0.003\right)$ and women $\left(P_{\text {trend }}<0.001\right)$. Our results suggest that higher Mn intakes may be protective against the MetS in men. The inverse association between Mn intake and the MetS in women might be due to the increased risk for low HDL-cholesterol.

Key words: Dietary intake: Manganese: Metabolic syndrome: TAG: HDL-cholesterol

Abdominal obesity, dyslipidaemia, hypertension and insulin resistance are well-established and strong risk factors of CVD and diabetes ${ }^{(1)}$. A highly significant trend was observed between the number of these risk factors and both CVD and all-cause mortality $^{(1)}$. In 1988, Reaven ${ }^{(2)}$ found that these factors commonly clustered together and consequently introduced the concept of the metabolic syndrome (MetS) for the first time. The MetS can be diagnosed on the basis of several indicators including waist circumference (WC), serum TAG, serum HDLcholesterol, systolic blood pressure (SBP) and diastolic blood pressure (DBP), and fasting blood glucose (FBG). As a multiplex risk factor for CVD, the MetS has received much clinical attention in recent years ${ }^{(3)}$. Although the prevalence of the MetS has reached a plateau in the USA in recent years (from $36.1 \%$ in
2007-2008 to $34.7 \%$ in 2011-2012) $)^{(4)}$, its prevalence has increased rapidly in developing countries. In China, the agestandardised prevalence of the MetS increased 4-fold from 5.4\% in 2002 to $21.3 \%$ in $2010^{(5)}$. Given its very large population size, development of effective strategies for MetS prevention is of great public health importance in China. A combination of environmental, genetic and lifestyle factors has been found to contribute to the development of the MetS. Recently, dietary intake has attracted much interest, as it offers a potentially modifiable prevention strategy ${ }^{(6)}$.

$\mathrm{Mn}$, as an essential mineral, is an enzyme cofactor and a constituent of metalloenzymes. Mn-containing polypeptides such as arginase and Mn-containing superoxide dismutase play important roles in enzyme activities and oxidative stress ${ }^{(7)}$.

Abbreviations: MetS, metabolic syndrome; WC, waist circumference

*Corresponding authors: G. Ding, fax +86 5718711 5242, email jhzb888@zju.edu.cn; R. Zhang, fax +86 57187115241 , email rhzhang@cdc.zj.cn

$\dagger$ Both authors contributed equally to this work. 
Insufficient Mn intake may have harmful health effects. Animal studies have found a link between dietary Mn and metabolisms of amino acids, lipids, proteins and carbohydrates ${ }^{(8,9)}$, suggesting that dietary Mn intake may be associated with some components of the MetS ${ }^{(10)}$. It has been suggested that Mn may be essential for maintaining lipoprotein structures because of its high affinity for complexing with the polar heads of phospholipids, thereby stabilising the lipoprotein particle $e^{(11,12)}$. Mn deficiency-induced oxidative stress accelerates proliferation of the vascular cells, causes blood vessel thickening and narrowing of the internal diameter as well as damages the endothelium, thus increasing vasoconstriction and the risk of hypertension ${ }^{(13)}$. In addition, impaired superoxide dismutase has also been shown to lead to significant deterioration indices of $\beta$-cell function, such as glucose-stimulated insulin secretion ${ }^{(14)}$.

$\mathrm{Mn}$ is rich in plant foods such as grains and rice, soyabeans, nuts, vegetables, fruits and tea. Previous studies have examined dietary $\mathrm{Mn}$ intake in different countries. Intake levels were found to vary substantially, from 1.38 to $11.0 \mathrm{mg} / \mathrm{d}^{(15-18)}$. However, thus far, a few studies with larger sample sizes have assessed the source and level of dietary Mn intake among Chinese adults ${ }^{(19)}$. These data are necessary if appropriate guidelines are to be developed for dietary Mn intake for the Chinese population.

Insufficient intakes of plant foods have been found to have adverse health effects including obesity, decreased glucose intolerance and cancer ${ }^{(20,21)}$. A few epidemiological studies have examined the association between Mn intake and MetS risk, and the results have not been consistent ${ }^{(19,22,23)}$. In one study conducted in 550 Chinese adults ${ }^{(19)}$, compared with participants in the lowest quartile ( $\mathrm{Mn}$ intake $<2.62 \mathrm{mg} / \mathrm{d}$ ), those in the highest quartile (Mn intake $>4.56 \mathrm{mg} / \mathrm{d}$ ) had a significantly lower risk of the MetS. However, no association was observed among Korean adults with similar quartile cutoffs of $\mathrm{Mn}$ intake ${ }^{(22,23)}$. More studies with a larger number of participants are needed to clarify this relationship.

The present study aimed to assess dietary intake levels and the main food sources of $\mathrm{Mn}$ in a Chinese population, and sought to examine the association between dietary Mn intake and the MetS as well as its components, using data from the 5th Chinese National Nutrition and Health Survey (CNNHS) conducted between 2010 and 2012

\section{Materials \\ Study population and sampling strategy}

The data used in this study were derived from a part of the 5th $\mathrm{CNNHS}^{(24)}$, which was conducted between 2010 and 2012. In this cross-sectional study, a stratified, multistage probability cluster sampling design was used to recruit participants. In the first stage, six sampling sites (two large cities in 2010, two small-medium cities in 2011 and two rural counties in 2012) were randomly selected in Zhejiang Province. In the second stage, six communities were randomly selected in each city or county, using a probability-proportional-to-size sampling scheme. In each community, twenty-five households constituted a cluster by geography of household addresses; three clusters were randomly selected, giving a total of seventyfive households. We used 3-d 24-h dietary recalls and FFQ as the major dietary assessment methods for this survey; 3-d 24-h dietary recalls were used in the twenty-five households in the first cluster and the first five households in the second cluster to estimate nutrient intakes and assess the associations with diseases. The remaining households completed FFQ to assess dietary intake in the past 12 months and/or instant food questionnaires. The survey was conducted between August and October in each of the calendar years 2010, 2011 and 2012.

Subjects younger than 18 years of age were excluded from the present analysis. Fig. 1 shows the flow chart of the survey. Initially, 8175 subjects (3908 men and 4267 women; 2700 households) were recruited, and 5774 adults (1800 households) participated in the FFQ and instant food dietary assessment (900 households completed the FFQ and 900 households completed the instant food questionnaires). Of the remaining 2401 adults (900 households) who completed the 3-d, 24-h dietary recalls, eighteen people were excluded (eight leaving home to work in other cities, five hospitalised and five due to other reasons). A total of 2384 adults (1142 men and 1242 women) completed the 24 -h dietary recalls. Of these, $273 \mathrm{did}$ not have information on physical and/or laboratory examination (fifty-two had only part of the information and 221 were missing all of the information); therefore, 2111 adults were included in the present analysis. The present study was approved by the Medical Ethics Committee of the Zhejiang Provincial Centre of Disease Control and Prevention, and written informed consent was obtained from all participants.

\section{Questionnaire surveys and 24- $h$ dietary recalls}

Questionnaire surveys, dietary assessments and physical examinations were conducted among all 2111 participants at a central survey site in their residential area. The questionnaire was administered face-to-face by trained interviewers to collect socio-demographic information including age, sex, area of residence, marital status, occupation, educational status, household income and lifestyle- and health-related information on smoking, alcohol consumption, physical activity, personal and family history of major chronic diseases, and history of medication.

Dietary intake was assessed in person by using unannounced 24-h dietary recalls on 3 consecutive days (2 weekdays and 1 weekend day). Participants were asked to recall everything they had eaten in the preceding $24 \mathrm{~h}$, including quantities. The foods included staple foods, snacks, fruits, vegetables, etc. Measuring guides were used to enhance recall and facilitate the estimation of an average portion size. Intakes of condiments were assessed by Weighed Diet Records. The nutrient contents of the diet were analysed, and the daily dietary nutrient intakes, including manganese, were calculated on the basis of the China Food Composition (2nd ed.) provided by the Chinese Nutrition Society ${ }^{(25)}$, which included Mn contents in 1506 foods.

\section{Anthropometric and laboratory measurements}

Anthropometric measurements including height, weight, BMI and WC were obtained for each adult participant by trained 


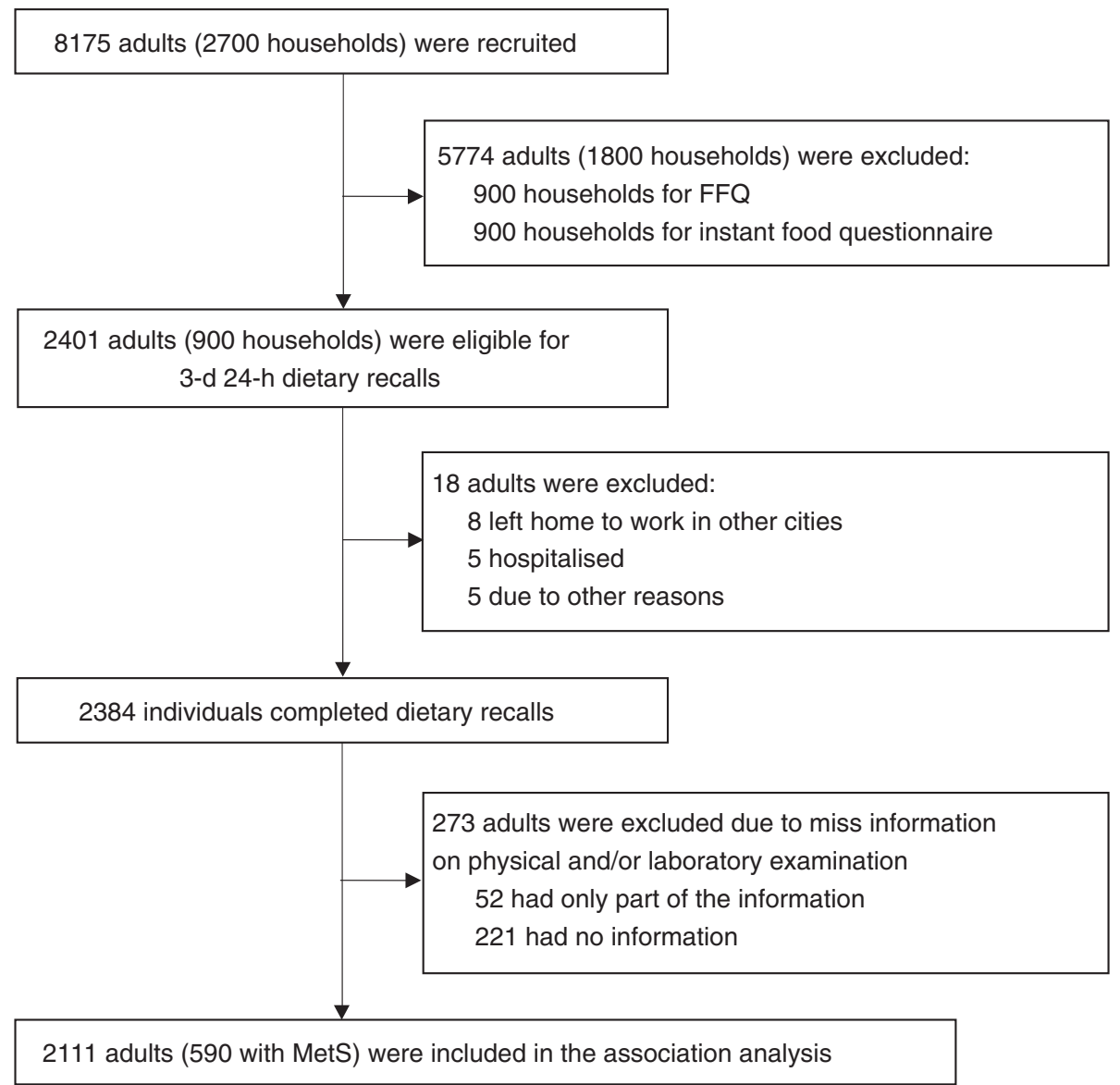

Fig. 1. Flow chart of the survey. MetS, metabolic syndrome.

field workers, following standard protocols. WC was measured to the nearest $0.1 \mathrm{~cm}$ at the midpoint between the top of the iliac crest and the lower margin of the last palpable rib in the midaxillary line using a tape measure. After $5 \mathrm{~min}$ of rest in the sitting position, SBP and DBP ( $\mathrm{mmHg}$, an accuracy of $2 \mathrm{mmHg}$ ) were measured using a mercury sphygmomanometer (YuwellJiangsu Yuyue Medical Equipment \& Supply Co., Ltd.) in the right arm with an appropriately sized cuff, in accordance with the Guidelines for Prevention and Treatment of Hypertension in China (2005); three consecutive readings each separated by 5-10 min were taken, and the mean values of the three measures were used for the analysis.

Venous blood samples were collected and measured in the local hospitals; $6 \mathrm{ml}$ of blood after fasting for $10-12 \mathrm{~h}$ was collected into a 2 -ml vacuum, lithium heparin anticoagulant tube and a 4-ml vacuum tube, respectively. Whole blood samples were centrifuged at $1500 \boldsymbol{g}$ for $10-15 \mathrm{~min}$. The serum collected in the 2-ml tube was separated for TAG ( $\mathrm{mmol} / \mathrm{l})$ and HDLcholesterol (mmol/l) measurements by an automatic biochemical analyser, and 20- $\mu$ l serum was separated from the 4-ml vacuum tube for FBG measurement. After the 6-ml fasting blood samples were collected, participants took $75 \mathrm{~g}$ glucose dissolved in $300 \mathrm{ml}$ water orally within $3 \mathrm{~min}$, and another blood sample was collected into a $2-\mathrm{ml}$ vacuum tube $2 \mathrm{~h}$ later $( \pm 3 \mathrm{~min})$. An additional $20 \mu \mathrm{l}$ of serum was separated after centrifugation at $1500 \mathrm{~g}$ for $10-15 \mathrm{~min}$ for an oral glucose tolerance test. The remaining blood samples were stored at $-70^{\circ} \mathrm{C}$.

The serum levels of TAG were measured using the glycerol phosphate oxidase-phenol amino phenazone (GPO-PAP) method and a Pars Azmoon kit (Pars Azmoon Inc.). Serum HDL-cholesterol levels were tested using the sedimentary method with the same kit using the Liasys autoanalyser device (Liasys). FBG was measured by the glucose oxidase method using the same auto-analyser device.

\section{Diagnostic criteria of the metabolic syndrome}

The MetS was diagnosed according to the American Heart Association and the National Heart, Lung and Blood Institute scientific statement ${ }^{(26)}$; the criterion of WC was appropriate for Asians. Participants were diagnosed as having the MetS if they met at least three of the following criteria: (1) abdominal obesity, WC $\geq 90 \mathrm{~cm}$ in men and $\mathrm{WC} \geq 80 \mathrm{~cm}$ in women; (2) hypertriacylglycerolaemia, TAG $\geq 1.7 \mathrm{mmol} / 1$ ( $150 \mathrm{mg} / \mathrm{dl})$ or on drug treatment for elevated TAG; (3) low HDL-cholesterol, HDL-cholesterol $<1.03 \mathrm{mmol} / \mathrm{l} \quad(40 \mathrm{mg} / \mathrm{dl})$ in men and HDL-cholesterol $<1.3 \mathrm{mmol} / \mathrm{l}(50 \mathrm{mg} / \mathrm{dl})$ in women or on drug treatment for reduced HDL-cholesterol; (4) hypertension, $\mathrm{SBP} / \mathrm{DBP} \geq 130 / 85 \mathrm{mmHg}$ or on antihypertensive drug treatment in patients with a history of hypertension; and 
(5) hyperglycaemia, FBG $\geq 5.56 \mathrm{mmol} / \mathrm{l}(100 \mathrm{mg} / \mathrm{dl})$ or on drug treatment for elevated blood glucose.

\section{Statistical analysis}

As sex was found to modify the association between Mn intake and the MetS, all analyses were performed for men and women separately. Demographic and lifestyle characteristics, intakes of Mn and other nutrients, and MetS components were compared using independent $t$ tests for continuous variables or $\chi^{2}$ tests for categorical variables between participants with and without the MetS by sex. Mn intake was the main exposure of interest. The residual method was used to calculate energy-adjusted Mn intakes, which were the residuals from a linear regression model with total energy intake as the independent variable and absolute Mn intake as the dependent variable. Energy-adjusted Mn values were divided into quartiles on the basis of the distributions among men and women, respectively, with the lowest quartile (Q1) as the reference group. To assess the associations between $\mathrm{Mn}$ intake and the risk of the MetS and its components, multivariable logistic regressions were used to estimate OR and $95 \% \mathrm{CI}$. The covariates that were significantly different in the univariate analyses were adjusted in the multivariable logistic models. The adjusted variables were age, area of residence, household income and total energy intake for men and age, area of residence, marital status, educational level, drinking status and intake of supplements, $\mathrm{Mg}$ and $\mathrm{Zn}$ for women. Linear trends were tested by entering the median values of quartiles as continuous variables in the regression. Multiplicative interactions were assessed by adding the interaction terms (sex $\times$ quartiles of $M n$ intake) and comparing the two models with and without the interaction terms using likelihood ratio test. We also explored the association between Mn intake and MetS risk using other cut-off points - for instance, above and below the minimum recommended $\mathrm{Mn}$ intake values.

All analyses were conducted using Statistical Package for the Social Sciences software version 17.0 (SPSS Inc.). All statistical tests were two-tailed, and a $P$ value $<0.05$ was considered statistically significant for the MetS analyses. For components of the MetS, considering that type I error may be inflated by multiple testing, $P$ values were adjusted using the Bonferroni correction by dividing the original $5 \%$ significance level by the number of components ( $P$ adjusted $=0 \cdot 05 / 5=0 \cdot 01$ ).

\section{Results}

\section{Study participants}

A total of 2111 adults were included in the analysis, of whom 590 were identified as having the MetS, resulting in a prevalence of $28.0 \%$. The mean age was 54.2 (SD 14.2) years for men and 52.1 (SD 14.0) years for women $(P=0.586)$. A significant difference in the mean daily intake of Mn was found between men and women (men: 6.07 (SD 2.94) mg/d; women: $5 \cdot 13(\mathrm{sD} 2 \cdot 65) \mathrm{mg} / \mathrm{d} ; P=0 \cdot 003)$.

Regardless of sex, participants with the MetS were older, more likely to live in large or small-to-medium cities and had a higher proportion of abdominal obesity, hypertriacylglycerolaemia, low HDL-cholesterol, hypertension and hyperglycaemia, compared with participants without the MetS (all $P<0.05$ ). In addition, male participants with the MetS had a higher WC, FPG, 2hPG (plasma glucose) and TAG than their counterparts without the MetS. Among women, participants with the MetS were less likely to have higher educational levels, be married and be drinkers, but they had higher levels of FPG, 2hPG, DBP and TAG and were more likely to use supplements (Table 1).

\section{Major food sources of manganese}

Table 2 lists different food sources of $\mathrm{Mn}$ and contribution percentages in the total sample and in various sampling sites. Only foods contributing to $\geq 2 \%$ of $\mathrm{Mn}$ intake are listed. Rice ( $>42 \%$ ) was the major food source of $\mathrm{Mn}$ for both men and women, regardless of MetS status in Zhejiang, China, followed by wheat flour (approximately 3\%) and noodles (approximately $3 \%$ ).

\section{Associations between manganese intake and the metabolic syndrome and its components}

Table 3 presents Mn intake in people with and without the MetS and its components by sex. The cut-off values were $5.12 \mathrm{mg} / \mathrm{d}$ for the lowest quartile and $6.87 \mathrm{mg} / \mathrm{d}$ for the highest quartile for men and $4.26 \mathrm{mg} / \mathrm{d}$ for the lowest quartile and $5.79 \mathrm{mg} / \mathrm{d}$ for the highest quartile for women. An inverse association was observed between Mn intake and the risk of the MetS among women, whereas a positive association was found among men, although both associations were of borderline significance (Table 3). Women in the highest quartile of $\mathrm{Mn}$ intake had a $38 \%$ lower risk of the MetS than women in the lowest quartile (Q4 v. Q1: multivariable OR 0.62 (95\% CI 0.42, 0.92); $P_{\text {trend }}=$ 0.043). Men with the highest intake of $\mathrm{Mn}$ had an increased risk of the MetS than their counterparts with the lowest intake (Q4 $v$. Q1: multivariable OR 1.56 (95\% CI 1.02, 2.45); $\left.P_{\text {trend }}=0.078\right)$. A significant interaction was found between $\mathrm{Mn}$ intake and sex $\left(P_{\text {for interaction }}=0 \cdot 002\right)$.

Significant interactions between $\mathrm{Mn}$ intake and sex were found for abdominal obesity $\left(P_{\text {for interaction }}=0.023\right.$ ) and hypertriacylglycerolaemia $\left(P_{\text {for interaction }}=0 \cdot 017\right)$. A higher Mn intake was marginally associated with lower risks of abdominal obesity $\left(P_{\text {trend }}=0.016\right)$ and hypertriacylglycerolaemia $\left(P_{\text {trend }}=0.029\right)$ among men, but not among women $\left(P_{\text {trend }}=0.990\right.$ for abdominal obesity; $P_{\text {trend }}=0.545$ for hypertriacylglycerolaemia). In addition, Mn intake was significantly and positively associated with low HDL-cholesterol risk for both women $\left(P_{\text {trend }}=0.003\right)$ and men $\left(P_{\text {trend }}<0.001\right)$. No significant association was found between $\mathrm{Mn}$ intake and hypertension or hyperglycaemia for both men and women.

The minimum safe level of $\mathrm{Mn}$ intake is $2 \mathrm{mg} / \mathrm{d}$ and the maximum safe level is $11 \mathrm{mg} / \mathrm{d}$ in China. As only twenty-one participants had a $\mathrm{Mn}$ intake $<2 \mathrm{mg} / \mathrm{d}$ and only twenty-four had an intake $>11 \mathrm{mg} / \mathrm{d}$, it was impossible for us to assess the associations using these cut-off values. We used the recommended intake level of $4.5 \mathrm{mg} / \mathrm{d}$ as the cut-off value to 


\section{NS British Journal of Nutrition}

Table 1. Demographic and lifestyle characteristics and metabolic syndrome (MetS)-related variables of the study population by sex

(Means values and standard deviations were presented for continuous variables; numbers and percentages were reported for categorical variables)

\begin{tabular}{|c|c|c|c|c|c|c|c|c|c|c|}
\hline \multirow[b]{3}{*}{ Variables } & \multicolumn{5}{|c|}{ Men } & \multicolumn{5}{|c|}{ Women } \\
\hline & \multicolumn{2}{|c|}{ MetS } & \multicolumn{2}{|c|}{ Non-MetS } & \multirow[b]{2}{*}{$P$} & \multicolumn{2}{|c|}{ MetS } & \multicolumn{2}{|c|}{ Non-MetS } & \multirow[b]{2}{*}{$P$} \\
\hline & Mean & SD & Mean & SD & & Mean & SD & Mean & SD & \\
\hline$n(\%)$ & 237 & $23 \cdot 7$ & 761 & $76 \cdot 3$ & - & 353 & 31.7 & 760 & $68 \cdot 3$ & - \\
\hline Age (years) & 56.5 & $12 \cdot 8$ & 53.5 & 14.5 & 0.010 & 59.0 & $11 \cdot 1$ & $48 \cdot 8$ & 14.0 & $<0.001$ \\
\hline $\mathrm{BMI}\left(\mathrm{kg} / \mathrm{m}^{2}\right)$ & $26 \cdot 3$ & 2.96 & 22.5 & 2.91 & 0.782 & $25 \cdot 3$ & 3.09 & 22.4 & 2.97 & 0.928 \\
\hline Area of residence & & & & & $<0.001$ & & & & & $<0.001$ \\
\hline \multicolumn{11}{|l|}{ Large cities } \\
\hline$n$ & \multicolumn{2}{|c|}{88} & \multicolumn{2}{|c|}{195} & & \multicolumn{2}{|c|}{122} & \multicolumn{2}{|c|}{256} & \\
\hline$\%$ & \multicolumn{2}{|c|}{37.1} & \multicolumn{2}{|c|}{$25 \cdot 6$} & & \multicolumn{2}{|c|}{34.6} & \multicolumn{2}{|c|}{33.7} & \\
\hline \multicolumn{11}{|l|}{ Small-medium cities } \\
\hline$n$ & \multirow{2}{*}{\multicolumn{2}{|c|}{$\begin{array}{c}102 \\
43 \cdot 0\end{array}$}} & \multirow{2}{*}{\multicolumn{2}{|c|}{$\begin{array}{l}293 \\
38.5\end{array}$}} & & & & & & \\
\hline$\%$ & & & & & & & & & & \\
\hline Rural counties & & & & & & & & & & \\
\hline$n$ & & & & & & & & & & \\
\hline$\%$ & & & & & & & & & & \\
\hline Marital status & & & & & 0.077 & & & & & 0.020 \\
\hline Married & & & & & & & & & & \\
\hline$n$ & & & & & & & & & & \\
\hline$\%$ & & & & & & & & & & \\
\hline Unmarried/divorced/widowed & & & & & & & & & & \\
\hline$n$ & & & & & & & & & & \\
\hline$\%$ & & & & & & & & & & \\
\hline Educational level & & & & & 0.925 & & & & & $<0.001$ \\
\hline Primary school or below & & & & & & & & & & \\
\hline$n$ & & & & & & & & & & \\
\hline$\%$ & & & & & & & & & & \\
\hline Secondary school & & & & & & & & & & \\
\hline$n$ & & & & & & & & & & \\
\hline$\%$ & & & & & & & & & & \\
\hline High school or above & & & & & & & & & & \\
\hline$n$ & & & & & & & & & & \\
\hline$\%$ & & & & & & & & & & \\
\hline Household income (yuan/year per person) & & & & & 0.001 & & & & & 0.404 \\
\hline$\leq 9999$ & & & & & & & & & & \\
\hline$n$ & & & & & & & & & & \\
\hline$\%$ & & & & & & & & & & \\
\hline $10000-19999$ & & & & & & & & & & \\
\hline$n$ & & & & & & & & & & \\
\hline$\%$ & & & & & & & & & & \\
\hline$\geq 20000$ & & & & & & & & & & \\
\hline$n$ & & & & & & & & & & \\
\hline$\%$ & & & & & & & & & & \\
\hline No response & & & & & & & & & & \\
\hline$n$ & & & & & & & & & & \\
\hline$\%$ & & & & & & & & & & \\
\hline
\end{tabular}


NS British Journal of Nutrition

Table 1. Continued

\begin{tabular}{|c|c|c|c|c|c|c|c|c|c|c|}
\hline \multirow[b]{3}{*}{ Variables } & \multicolumn{5}{|c|}{ Men } & \multicolumn{5}{|c|}{ Women } \\
\hline & \multicolumn{2}{|c|}{ MetS } & \multicolumn{2}{|c|}{ Non-MetS } & \multirow[b]{2}{*}{$P$} & \multicolumn{2}{|c|}{ MetS } & \multicolumn{2}{|c|}{ Non-MetS } & \multirow[b]{2}{*}{$P$} \\
\hline & Mean & SD & Mean & SD & & Mean & SD & Mean & SD & \\
\hline Smoking status ${ }^{\star}$ & & & & & $0 \cdot 136$ & & & & & 0.654 \\
\hline \multicolumn{11}{|l|}{ Yes } \\
\hline$n$ & \multirow{2}{*}{\multicolumn{2}{|c|}{$\begin{array}{c}116 \\
48.9\end{array}$}} & \multicolumn{2}{|c|}{415} & & \multicolumn{2}{|c|}{2} & \multicolumn{2}{|c|}{3} & \\
\hline$\%$ & & & & & & & & & & \\
\hline \multicolumn{11}{|l|}{ No } \\
\hline$n$ & \multicolumn{2}{|c|}{121} & \multicolumn{2}{|c|}{345} & & \multicolumn{2}{|c|}{347} & \multicolumn{2}{|c|}{750} & \\
\hline$\%$ & & & & & & & & & & \\
\hline Drinking status $†$ & & & & & 0.295 & & & & & 0.009 \\
\hline Yes & & & & & & & & & & \\
\hline$n$ & & & & & & & & & & \\
\hline$\%$ & & & & & & & & & & \\
\hline No & & & & & & & & & & \\
\hline$n$ & & & & & & & & & & \\
\hline$\%$ & & & & & & & & & & \\
\hline Supplements intake $\ddagger$ & & & & & 0.095 & & & & & 0.007 \\
\hline Yes & & & & & & & & & & \\
\hline$n$ & & & & & & & & & & \\
\hline$\%$ & & & & & & & & & & \\
\hline No & & & & & & & & & & \\
\hline$n$ & & & & & & & & & & \\
\hline$\%$ & & & & & & & & & & \\
\hline Energy intake $(\mathrm{kJ} / \mathrm{d})$ & 8602 & 3473 & 8410 & 3347 & 3.347 & 6406 & 2540 & 6899 & 2887 & 0.309 \\
\hline Energy intake $(\mathrm{kcal} / \mathrm{d})$ & 2056 & 830 & 2010 & 800 & 0.800 & 1531 & 607 & 1649 & 690 & 0.074 \\
\hline Mn intake $(\mathrm{mg} / \mathrm{d})$ & 5.94 & $2 \cdot 04$ & 6.08 & 2.05 & 0.200 & $5 \cdot 34$ & 1.47 & $5 \cdot 18$ & 1.98 & 0.053 \\
\hline $\mathrm{Ca}(\mathrm{mg} / \mathrm{d})$ & $508 \cdot 8$ & $262 \cdot 3$ & 454.4 & 243.9 & 0.426 & 417.4 & $236 \cdot 2$ & $421 \cdot 0$ & 250.9 & 0.564 \\
\hline $\mathrm{Mg}(\mathrm{mg} / \mathrm{d})$ & 313.0 & 124.6 & 298.2 & $125 \cdot 1$ & 0.954 & $256 \cdot 2$ & 101.0 & 263.3 & $130 \cdot 4$ & 0.043 \\
\hline $\mathrm{Zn}(\mathrm{mg} / \mathrm{d})$ & $12 \cdot 5$ & 4.94 & 11.7 & 4.67 & 0.261 & 9.43 & 3.59 & $10 \cdot 13$ & 4.95 & 0.015 \\
\hline $\mathrm{Fe}(\mathrm{mg} / \mathrm{d})$ & 24.6 & 11.5 & $22 \cdot 4$ & $10 \cdot 8$ & 0.067 & $19 \cdot 6$ & 13.6 & $20 \cdot 3$ & $16 \cdot 1$ & 0.510 \\
\hline$W C(\mathrm{~cm})$ & $93 \cdot 1$ & 7.87 & 80.9 & 8.68 & 0.004 & 86.5 & 8.22 & 76.6 & 8.36 & 0.762 \\
\hline FPG (mmol/l) & $6 \cdot 23$ & 1.63 & $5 \cdot 15$ & 1.15 & $<0.001$ & $6 \cdot 23$ & 1.60 & 5.07 & $1 \cdot 13$ & $<0.001$ \\
\hline $2 \mathrm{hPG}(\mathrm{mmol} / \mathrm{l})$ & 6.92 & 3.27 & 5.66 & $2 \cdot 22$ & $<0.001$ & 7.51 & 3.31 & 5.62 & 1.81 & $<0.001$ \\
\hline $\mathrm{SBP}(\mathrm{mmHg})$ & 135.9 & $15 \cdot 0$ & 121.9 & $16 \cdot 3$ & 0.249 & 135.9 & 17.9 & $117 \cdot 0$ & $16 \cdot 6$ & 0.062 \\
\hline $\mathrm{DBP}(\mathrm{mmHg})$ & 84.7 & 8.99 & $76 \cdot 9$ & $9 \cdot 37$ & 0.486 & $81 \cdot 2$ & 9.05 & 74.0 & $9 \cdot 28$ & 0.042 \\
\hline TAG $(\mathrm{mmol} / \mathrm{l})$ & $2 \cdot 86$ & 1.99 & 1.59 & 1.21 & $<0.001$ & $2 \cdot 33$ & 1.42 & 1.35 & 0.89 & $<0.001$ \\
\hline HDL-cholesterol (mmol/l) & 1.33 & 0.29 & 1.35 & 0.26 & 0.081 & 1.37 & 0.27 & 1.44 & 0.27 & 0.584 \\
\hline Abdominal obesity & & & & & $<0.001$ & & & & & $<0.001$ \\
\hline Yes & & & & & & & & & & \\
\hline$n$ & & & & & & & & & & \\
\hline$\%$ & & & & & & & & & & \\
\hline No & & & & & & & & & & \\
\hline$n$ & & & & & & & & & & \\
\hline$\%$ & & & & & & & & & & \\
\hline Hypertriacylglycerolaemia & & & & & $<0.001$ & & & & & $<0.001$ \\
\hline Yes & & & & & & & & & & \\
\hline$n$ & & & & & & & & & & \\
\hline$\%$ & & & & & & & & & & \\
\hline
\end{tabular}




\section{NS British Journal of Nutrition}

Table 1. Continued

\begin{tabular}{|c|c|c|c|c|c|c|c|c|c|c|}
\hline \multirow[b]{3}{*}{ Variables } & \multicolumn{5}{|c|}{ Men } & \multicolumn{5}{|c|}{ Women } \\
\hline & \multicolumn{2}{|l|}{ MetS } & \multicolumn{2}{|c|}{ Non-MetS } & \multirow[b]{2}{*}{$P$} & \multicolumn{2}{|l|}{ MetS } & \multicolumn{2}{|c|}{ Non-MetS } & \multirow[b]{2}{*}{$P$} \\
\hline & Mean & SD & Mean & SD & & Mean & SD & Mean & SD & \\
\hline \multicolumn{11}{|l|}{ No } \\
\hline$n$ & 44 & & & & & 101 & & & & \\
\hline$\%$ & $18 \cdot 7$ & & & & & 28.9 & & & & \\
\hline Low HDL-cholesterol & & & & & $<0.001$ & & & & & $<0.001$ \\
\hline \multicolumn{11}{|l|}{ Yes } \\
\hline$n$ & 41 & & & & & 163 & & & & \\
\hline$\%$ & $17 \cdot 4$ & & & & & $46 \cdot 7$ & & & & \\
\hline \multicolumn{11}{|l|}{ No } \\
\hline$n$ & 194 & & & & & 186 & & & & \\
\hline$\%$ & $82 \cdot 6$ & & & & & $53 \cdot 3$ & & & & \\
\hline Hypertension & & & & & $<0.001$ & & & & & $<0.001$ \\
\hline \multicolumn{11}{|l|}{ Yes } \\
\hline$n$ & 214 & & & & & 291 & & & & \\
\hline$\%$ & $90 \cdot 3$ & & & & & $82 \cdot 4$ & & & & \\
\hline \multicolumn{11}{|l|}{ No } \\
\hline$n$ & 23 & & & & & 62 & & & & \\
\hline$\%$ & 9.7 & & & & & $17 \cdot 6$ & & & & \\
\hline Hyperglycaemia & & & & & $<0.001$ & & & & & $<0.001$ \\
\hline \multicolumn{11}{|l|}{ Yes } \\
\hline$n$ & 167 & & & & & 236 & & & & \\
\hline$\%$ & $71 \cdot 1$ & & & & & 67.4 & & & & \\
\hline \multicolumn{11}{|l|}{ No } \\
\hline$n$ & 68 & & & & & 114 & & & & \\
\hline$\%$ & 28.9 & & & & & $32 \cdot 6$ & & & & \\
\hline
\end{tabular}

2h PG, 2-h plasma glucose; DBP, diastolic blood pressure; FPG, fasting plasma glucose; SBP, systolic blood pressure; WC, waist circumference. * Smoking was defined as having currently smoked $\geq 1$ cigarette daily for at least 30 consecutive days.

Ales drinking was defined as currently having had alcoholic beverages $\geq 0$ co daily for at least 30 consecutive days.

† Supplements mainly included Ca, vitamin D, fish oil, vitamins (multi-vitamins, vitamin A, vitamin B, vitamin C and vitamin $E$ ) and Ginkgo spirulina. 
re-calculate the risk. The results were similar but less informative than the results using quartiles (data not shown).

\section{Discussion}

Our results indicated that Mn intake was sufficient and in the safe range in this Chinese adult population in Zhejiang Province, China. The major food source of Mn was rice. High dietary Mn intake was associated with a decreased risk of the MetS, abdominal obesity and hypertriacylglycerolaemia among men, but an increased risk of the MetS among women, and an increased risk of low HDL-cholesterol among both men and women.

\section{Daily dietary intake of manganese}

According to the Chinese Nutrition Society ${ }^{(25)}$, the minimum safe level of $\mathrm{Mn}$ intake is $2 \mathrm{mg} / \mathrm{d}$, the maximum safe level is $11 \mathrm{mg} / \mathrm{d}$ and the recommended intake level is $4.5 \mathrm{mg} / \mathrm{d}$ in China. The average daily intake of $\mathrm{Mn}$ in this study population (men: 6.07 (sD 2.94$) \mathrm{mg} / \mathrm{d}$; women: 5.13 (sD 2.65 ) $\mathrm{mg} / \mathrm{d}$ ) was higher than the recommended intake level but lower than the maximum safe level. Our results indicated that Mn intake was sufficient in this Chinese adult population. Previous studies have shown that the mean intake of Mn varied substantially from 1.38 to $11.0 \mathrm{mg} / \mathrm{d}$ across different countries ${ }^{(15-18,27-30)}$. In general, the mean Mn intake level among participants in our study was similar to those of other Asian populations (e.g. $5.0 \mathrm{mg} / \mathrm{d}$ for Japanese ${ }^{(27)} ; 4.18 \mathrm{mg} / \mathrm{d}$ for Koreans $\left.{ }^{(28)}\right)$ but higher than European populations (e.g. $2.6 \mathrm{mg} / \mathrm{d}$ for Belgian ${ }^{(11)}$; $2.37 \mathrm{mg} / \mathrm{d}$ for Spanish $\left.{ }^{(30)}\right)$. The different Mn intake levels may be explained by various dietary patterns in different countries and different Mn contents in various types of foods.

\section{Major food sources of manganese in Chinese populations}

Rice (>42\%) was the main food source of Mn in this study. Similar results were also observed in a study conducted among Korean children, which found that cereals $(57.3 \%)$ contributed the most to Mn intake ${ }^{(31)}$. This is because Mn can be accumulated in rice through incorporation into proteins with superoxide dismutase activity ${ }^{(32)}$, and Chinese dietary patterns, particularly those in southern China, typically have rice as the staple supplemented by wheat. Zhejiang Province is well known as a centre for rice production, and this may explain why an adequate intake level of Mn was found in this study and also why higher mean intake levels were found in our study population compared with European populations.

\section{Associations between manganese intake and metabolic syndrome and its components}

Our study found that a higher Mn intake was associated with a decreased risk of the MetS for men but an increased MetS risk for women. To our knowledge, only a few studies have examined the associations between Mn intake and the risk of the MetS and its components ${ }^{(19,22,23)}$. No association was observed in two cross-sectional studies conducted among 
Table 3. Dietary manganese intake and relative risk (RR) of metabolic syndrome (MetS) and its components by sex (Relative risks and $95 \%$ confidence interval)

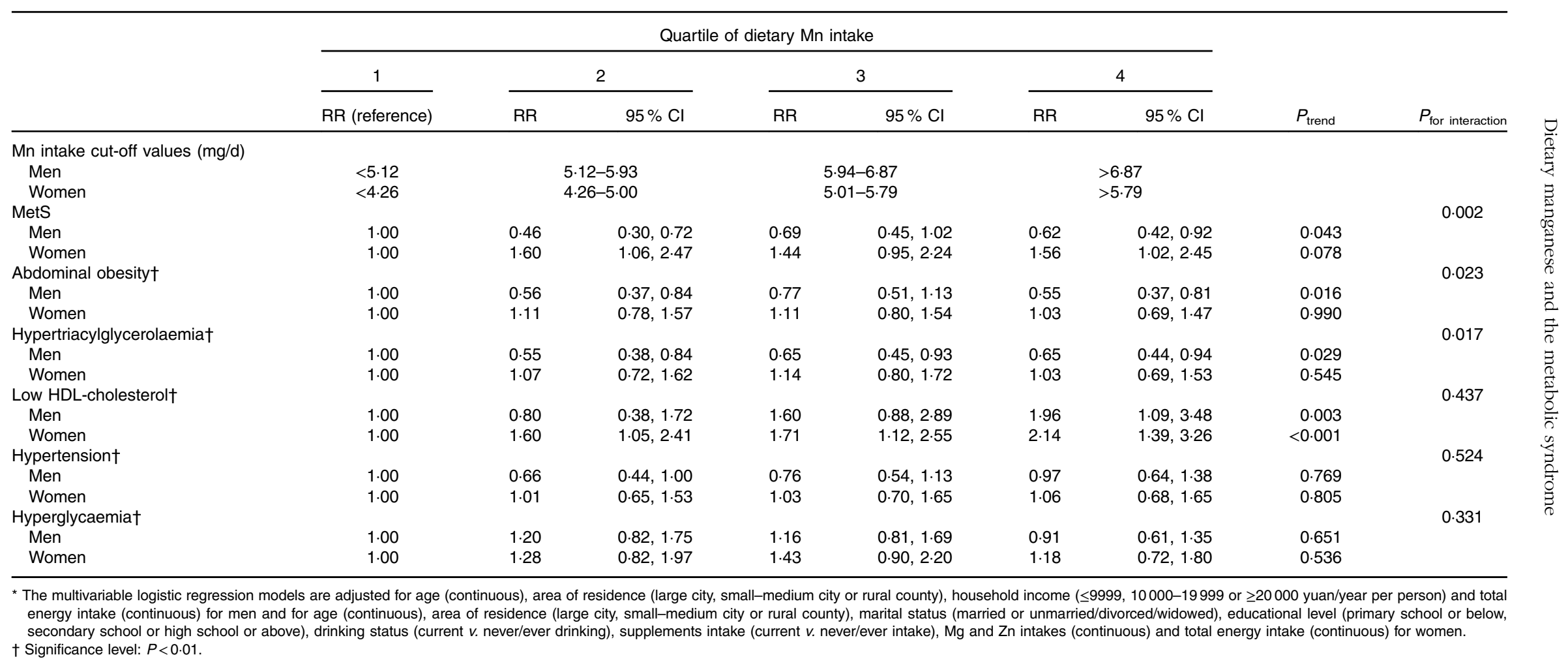


Korean adults, using data from the Korea National Health and Nutrition Examination Survey ${ }^{(22,23)}$. The inverse association observed among men in our study was consistent with the results from another cross-sectional study conducted by $\mathrm{Li}$ et $a l .{ }^{(19)}$ among 550 Chinese adults. In that study, participants in the highest quartile of $\mathrm{Mn}$ intake had a $53 \%$ (95\% CI 21, 71\%) lower risk of the MetS than those in the lowest quartile ${ }^{(19)}$. However, sex difference was not further explored in the study by Li et al. ${ }^{(19)}$ because of the limited number of participants ${ }^{(19)}$. Differences in CVD or metabolic disease risk by sex have been suggested due to differences in oestrogen and androgen levels, HDL dysfunction and gene-environment interactions ${ }^{(33,34)}$. With a larger sample size, we were able to conduct a stratified analysis and found that the association between $\mathrm{Mn}$ intake and MetS risk was modified by sex. More research is needed to confirm the potential effect modification by sex observed in our study.

For MetS components, we found a significant inverse association between $\mathrm{Mn}$ intake and the risk of abdominal obesity and hypertriacylglycerolaemia for men, but a positive association with low HDL-cholesterol, and no association with hypertension and hyperglycaemia for both men and women. Our results differ from those obtained by Choi \& $\mathrm{Kim}^{(22)}$, who found no association for obesity, TAG, glucose and HDLcholesterol, but observed that participants with higher Mn intake had lower BP. However, the findings from our study are consistent with those of previous small intervention trials, in which Mn supplementation has been found to be important in reducing obesity and regulating blood lipid metabolism. A small clinical trial with fourteen adults reported that Mn gluconate supplementation of diets, combined with either calcium phosphate or calcium carbonate, increased faecal excretion of fat, thus decreasing body fat ${ }^{(35)}$. Another clinical trial found that a Mn-adequate diet of conventional foods could decrease plasma levels of cholesterol in seven men aged 19-22 years ${ }^{(36)}$. Evidence from animal studies also provides biological support for the potential role of $\mathrm{Mn}$ in MetS prevention. Mn supplement or intake could reduce abdominal fat accumulation by decreasing fatty acid synthase and malate dehydrogenase activities in the liver ${ }^{(37)}$ and glycerol in adipose tissue ${ }^{(38)}$, as well as decrease total cholesterol, LDL-cholesterol and HDLcholesterol because Mn may be an essential component of the lipoprotein structure ${ }^{(13,39)}$. However, to our knowledge, no study has examined the different effects of Mn intake on the MetS and its components by sex. Given the biological evidence and the inconsistent results of the cross-sectional studies, more studies, particularly large cohort studies with long-time followup and full adjustment of confounders, are needed to further confirm the association between $\mathrm{Mn}$ intake and the risk of the MetS and its components, particularly for males and females.

\section{Strengths and limitations}

A major strength of this study is the relatively large number of participants to explore the different associations among males and females, which has not been assessed in previous studies. The stratified, multistage probability cluster sampling method ensures the representativeness of the study sample. The use of the 3-d 24-h recall dietary assessment method provided detailed dietary intake information to allow for an accurate estimation of Mn intake. Finally, the diagnosis of the MetS and its components was based on objective physical and laboratory measurements, which reduced the likelihood of misclassification.

This study has several limitations. First, it was a cross-sectional study, making it difficult to establish a cause-and-effect relationship. Second, only confounders such as age, sex, residential area, smoking status, alcohol intake and total energy intake were adjusted for in the multivariable analyses. Other potential confounders such as physical activity were not adjusted for. Third, although 24-h dietary recalls are widely used as a standard dietary assessment method, using biomarkers may provide more objective measurements of the biologically available and active levels of $\mathrm{Mn}$. However, limited funding prevented us from measuring blood levels of $\mathrm{Mn}$.

In conclusion, this study found that rice was the main food source of $\mathrm{Mn}$ among Chinese adults in Zhejiang Province, China. A higher Mn intake (e.g. $>5.12 \mathrm{mg} / \mathrm{d}$ ) was associated with a reduced risk of the MetS and its two components abdominal obesity and hypertriacylglycerolaemia - among men, whereas a positive association was observed between Mn intake (e.g. $>4.26 \mathrm{mg} / \mathrm{d}$ ) and the risk of the MetS and low HDL-cholesterol among women. As diet is potentially modifiable, increasing $\mathrm{Mn}$ intake while maintaining a safe level may suggest a potential strategy for the prevention of some components of the MetS for men.

\section{Acknowledgements}

The authors acknowledge the local governments that supported the survey. The authors also thank the survey participants and the interviewers from local Centres of Disease Control and Prevention who implemented the survey and conducted data entry.

The Chinese National Nutrition and Health Survey was supported by the China Ministry of Health Special Fund and the China Ministry of Science and Technology Key Research Fund. The sponsor had no role in the design, analysis or writing of this article.

G. D. was responsible for conception and design, acquisition of funding and overseeing the study, interpretation of data and manuscript editing. B. Z. and X. S. were in charge of the design, data collection, analysis and interpretation of data and manuscript writing. D. S., F. Z. and M. H. W. contributed to data analysis and interpretation. L. H., E. H., Y. Z., D. Z., D. H. and X. Z. contributed to fieldwork data collection and cleaning and manuscript drafting. E. Y. contributed to interpretation of the data and manuscript editing. R. Z. was in charge of study coordination and quality control, interpretation of the data and manuscript editing.

The authors declare no conflicts of interest.

\section{References}

1. Ho JS, Cannaday JJ, Barlow CE, et al. (2008) Relation of the number of metabolic syndrome risk factors with all-cause and cardiovascular mortality. Am J Cardiol 102, 689-692. 
2. Reaven GM (1988) Banting lecture 1988. Role of insulin resistance in human disease. Diabetes 37, 1595-1607.

3. Grundy SM (2007) Metabolic syndrome: a multiplex cardiovascular risk factor. J Clin Endocrinol Metab 92, 399-404.

4. Aguilar M, Bhuket T, Torres S, et al. (2015) Prevalence of the metabolic syndrome in the United States, 2003-2012. JAMA 313, 1973-1974.

5. Lao XQ, Ma WJ, Sobko T, et al. (2014) Dramatic escalation in metabolic syndrome and cardiovascular risk in a Chinese population experiencing rapid economic development. $B M C$ Public Health 14, 983.

6. Bassi N, Karagodin I, Wang S, et al. (2014) Lifestyle modification for metabolic syndrome: a systematic review. Am J Med 127, 1242 e1241-e1210.

7. Yamashita N, Nishida M, Hoshida S, et al. (1994) Induction of manganese superoxide-dismutase in rat cardiac myocytes increases tolerance to hypoxia 24 hours after preconditioning. J Clin Invest 94, 2193-2199.

8. Keen CL, Ensunsa JL, Watson MH, et al. (1999) Nutritional aspects of manganese from experimental studies. Neurotoxicology 20, 213-223.

9. Szentmihalyi K, Vinkler P, Fodor J, et al. (2006) The role of manganese in the human organism. Orv Hetil 147, 2027-2030.

10. Keen CL, Baly DL \& Lonnerdal B (1984) Metabolic effects of high doses of manganese in rats. Biol Trace Elem Res 6 , 309-315.

11. Barak A, Keefer R \& Tuma D (1971) The possible role of manganese in hepatic lipid transport. Nutr Rep Int 3, 243-246.

12. Puskin JS \& Martin T (1979) Divalent cation binding to phospholipid veiscles. Dependence on temperature and lipid fluidity. Biochim Biophys Acta 552, 53-65.

13. Lee YK, Lyu ES, Oh SY, et al. (2015) Daily copper and manganese intakes and their relation to blood pressure in normotensive adults. Clin Nutr Res 4, 259-266.

14. Kang L, Dai C, Lustig ME, et al. (2014) Heterozygous SOD2 deletion impairs glucose-stimulated insulin secretion, but not insulin action, in high-fat-fed mice. Diabetes $\mathbf{6 3}$, 3699-3710.

15. Robberecht HJ, Hendrix P, Van Cauwenbergh R, et al. (1994) Daily dietary manganese intake in Belgium, using duplicate portion sampling. Z Lebensm Unters Forsch 199, 446-448.

16. Tripathi RM, Mahapatra S, Raghunath R, et al. (2000) Daily intake of manganese by the adult population of Mumbai. Sci Total Environ 250, 43-50.

17. Leblanc JC, Guerin T, Noel L, et al. (2005) Dietary exposure estimates of 18 elements from the 1st French Total Diet Study. Food Addit Contam 22, 624-641.

18. Rose M, Baxter M, Brereton N, et al. (2010) Dietary exposure to metals and other elements in the 2006 UK Total Diet Study and some trends over the last 30 years. Food Addit Contam Part A Chem Anal Control Expo Risk Assess 27, 1380-1404.

19. Li Y, Guo H, Wu M, et al. (2013) Serum and dietary antioxidant status is associated with lower prevalence of the metabolic syndrome in a study in Shanghai, China. Asia Pac J Clin Nutr 22, 60-68.

20. Aschner M, Guilarte TR, Schneider JS, et al. (2007) Manganese: recent advances in understanding its transport and neurotoxicity. Toxicol Appl Pharmacol 221, 131-147.

21. Zablocka-Slowinska K \& Grajeta H (2012) The role of manganese in etiopathogenesis and prevention of selected diseases. Postepy Hig Med Dosw (Online) 66, 549-553.
22. Choi M \& Kim E (2007) Evaluation of dietary manganese intake in Korean men and women over 20 years old. $J$ Korean Soc Food Sci Nutr 36, 447-452.

23. Rhee SY, Hwang YC, Woo JT, et al. (2013) Blood lead is significantly associated with metabolic syndrome in Korean adults: an analysis based on the Korea National Health and Nutrition Examination Survey (KNHANES), 2008. Cardiovasc Diabetol 12, 9.

24. Wu Y, Huxley R, Li L, et al. (2008) Prevalence, awareness, treatment, and control of hypertension in China: data from the China National Nutrition and Health Survey 2002. Circulation 118, 2679-2686.

25. Yang YX, Wang GY \& Pan XC (2009) China Food Composition Table, 2nd ed. Beijing: Peking University Medical Press.

26. Grundy SM, Cleeman JI, Daniels SR, et al. (2005) Diagnosis and management of the metabolic syndrome - an American Heart Association/National Heart, Lung, and Blood Institute Scientific statement. Circulation 112, 2735-2752.

27. Yamada M, Asakura K, Sasaki S, et al. (2014) Estimation of intakes of copper, zinc, and manganese in Japanese adults using 16-day semi-weighed diet records. Asia Pac J Clin Nutr 23, 465-472.

28. Choi MK \& Bae YJ (2013) Relationship between dietary magnesium, manganese, and copper and metabolic syndrome risk in Korean adults: the Korea National Health and Nutrition Examination Survey (2007-2008). Biol Trace Elem Res 156, 56-66.

29. Buchet JP, Lauwerys R, Vandevoorde A, et al. (1983) Oral daily intake of cadmium, lead, manganese, copper, chromium, mercury, calcium, zinc and arsenic in Belgium: a duplicate meal study. Food Chem Toxicol 21, 19-24.

30. Rubio C, Gutierrez AJ, Revert C, et al. (2009) Daily dietary intake of iron, copper, zinc and manganese in a Spanish population. Int J Food Sci Nutr 60, 590-600.

31. Bae YJ \& Choi MK (2011) The estimated daily manganese intake of Korean children aged 11-12. Nutr Res Pract 5, 548-552.

32. Lidon FC, Barreiro MG \& Ramalho JC (2004) Manganese accumulation in rice: implications for photosynthetic functioning. J Plant Physiol 161, 1235-1244.

33. Onat A, Karadeniz Y, Tusun E, et al. (2016) Advances in understanding gender difference in cardiometabolic disease risk. Expert Rev Cardiovasc Ther 14, 513-523.

34. Mihailidou AS \& Ashton AW (2014) Cardiac effects of aldosterone: does gender matter? Steroids $\mathbf{9 1}, 32-37$.

35. Potter SM, Kies CV \& Rojhani A (1990) Protein and fat utilization by humans as affected by calcium-phosphate, calcium-carbonate, and manganese gluconate supplements. Nutrition 6, 309-312.

36. Friedman BJ, Freelandgraves JH, Bales CW, et al. (1987) Manganese balance and clinical observations in young men fed a manganese-deficient diet. J Nutr 117, 133-143.

37. Wang M, Chen Z, Lu L, et al. (2011) Effect of different manganese sources on activities and gene expression of key enzymes in fat metabolism of broilers. Scientia Agricultura Sinica 44, 3850-3858.

38. Baquer NZ, Sinclair M, Kunjara S, et al. (2003) Regulation of glucose utilization and lipogenesis in adipose tissue of diabetic and fat fed animals: effects of insulin and manganese. J Biosci 28, 215-221.

39. Bae YJ, Choi MK \& Kim MH (2011) Manganese supplementation reduces the blood cholesterol levels in Ca-deficient ovariectomized rats. Biol Trace Elem Res 141, 224-231. 